\title{
SIZE REDUCTION OF HEMISPHERICAL EXPLOSIVE SHELLS BY WATERJET
}

\author{
James A. Crutchmer \\ Binh T. Do \\ Phillip A. Goodfellow
}

Production Capability Assurance Program
Current Issues
(PX-3-0002-93)

KEYWORDS:

Size Reduction, Waterjet, Spiral, Recycle, Dismantlement, Stockpile, Machining,

\section{FEBRUARY 1995}

Confirmed to be Unclassified

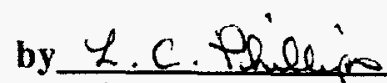

Authorized Classifier

Date: $2-6-95$ 


\section{DISCLAIMER}

This report was prepared as an account of work sponsored by an agency of the United States Government. Neither the United States Government nor any agency thereof, nor any of their employees, make any warranty, express or implied, or assumes any legal liability or responsibility for the accuracy, completeness, or usefulness of any information, apparatus, product, or process disclosed, or represents that its use would not infringe privately owned rights. Reference herein to any specific commercial product, process, or service by trade name, trademark, manufacturer, or otherwise does not necessarily constitute or imply its endorsement, recommendation, or favoring by the United States Government or any agency thereof. The views and opinions of authors expressed herein do not necessarily state or reflect those of the United States Government or any agency thereof. 


\section{DISCLAIMER}

Portions of this document may be illegible in electronic image products. Images are produced from the best available original document. 


\title{
SIZE REDUCTION OF HEMISPHERICAL EXPLOSIVE SHELLS BY WATERJET
}

\author{
James A. Crutchmer \\ Binh T. Do \\ Phillip A. Goodfellow
}

FEBRUARY 1995

Production Capability Assurance Program

Current Issues

(PX-3-0002-93)

\begin{abstract}
A water jet process has been developed to reduce hemispherical explosive shells to a form that can be recycled. A funnel shaped wet box was modified to hold the shells in place and contain all the explosive chips and slurry generated by the waterjet process. Size reduction was accomplished by cutting in spiral patterns starting at the center of the shell and moving outward. This method of size reduction produces less than one third the amount of waste water and requires less than one half the time to complete compared to conventional machining methods.
\end{abstract}




\section{INTRODUCTION}

The dismantlement of U.S. nuclear and conventional weapons arsenals has yielded a huge stockpile of explosive and propellant parts which need to be either destroyed or converted to a usable form that can be recycled. Several methods have been used in the past to solve these problems. Open burning and detonation have been used to destroy explosive shells and other components. Conventional machining has been used to reduce explosive shells to sizes that can be destroyed by open burning, and more recently, to a form that can be reprocessed. Explosive parts have also been reduced in size by underwater grinding.

Alternatives to open burning and detonation are being evaluated because these methods are no longer environmentally acceptable processes.

Conventional machining processes are labor intensive and generate a significant waste stream.

Underwater grinding is not desirable because it requires dedicated equipment that is expensive, spatially bulky and not very versatile.

\section{DISCUSSION}

Waterjet experiments have been conducted to reduce hemispherical test shells of LX-10 to a form that can be easily reprocessed. The experiments were conducted on our Ingersoll-Rand 5-axis gantry waterjet system shown in Figure 1. The high pressure intensifier for this system is driven by a 40 HP pump which can produce a flow rate of 1 gallon/minute at 55,000 psi. The 5-axis gantry is operated by an Allen-Bradley 8200 controller.

A large aluminum funnel, 23-inches diameter $x$ 14-inches high, was modified to hold the explosive shells and to contain the splatter from the waterjet. Figure 2 shows a top view of the funnel without the explosive shell in place. Splatter was controlled with a Plexiglas lid attached to the cutting head and covering the top of the funnel. The 4-inch diameter outlet in the bottom of the funnel was covered with 0.5-inch stainless steel mesh, as shown in Figure 2, to prevent large pieces of the explosive from falling through. A 1- $\mu$ cloth filter sock was attached to the outlet of the funnel to collect the explosive particles as they passed through the mesh. Figure 3 shows the filter sock attached to the funnel and the Plexiglas cover attached to the cutting head. 
pəy!ssejoun

$-\varepsilon-$

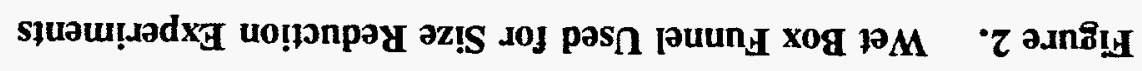

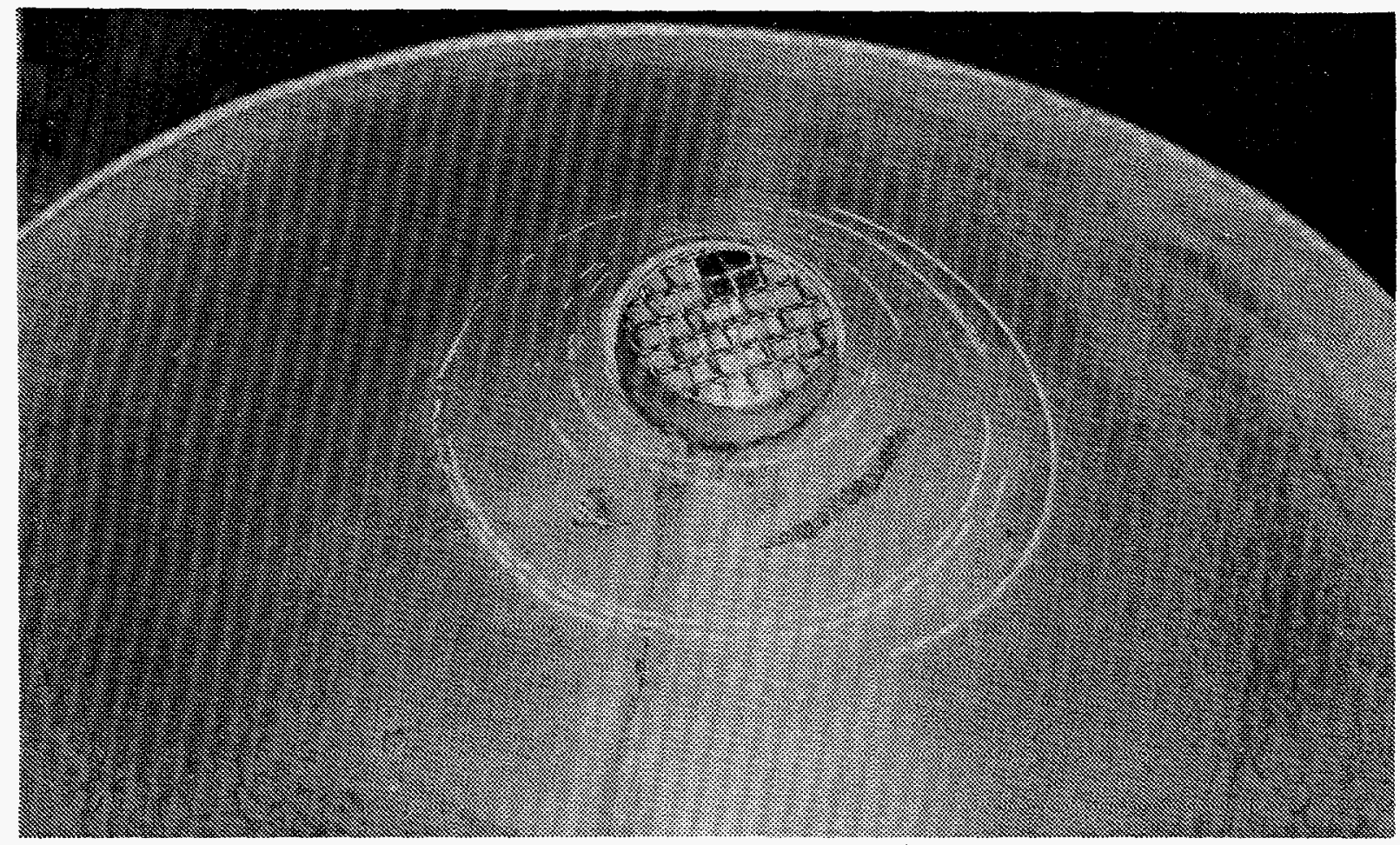

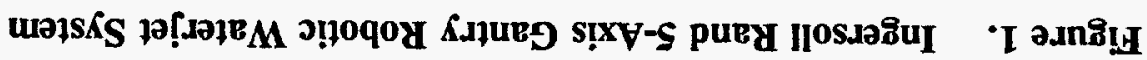

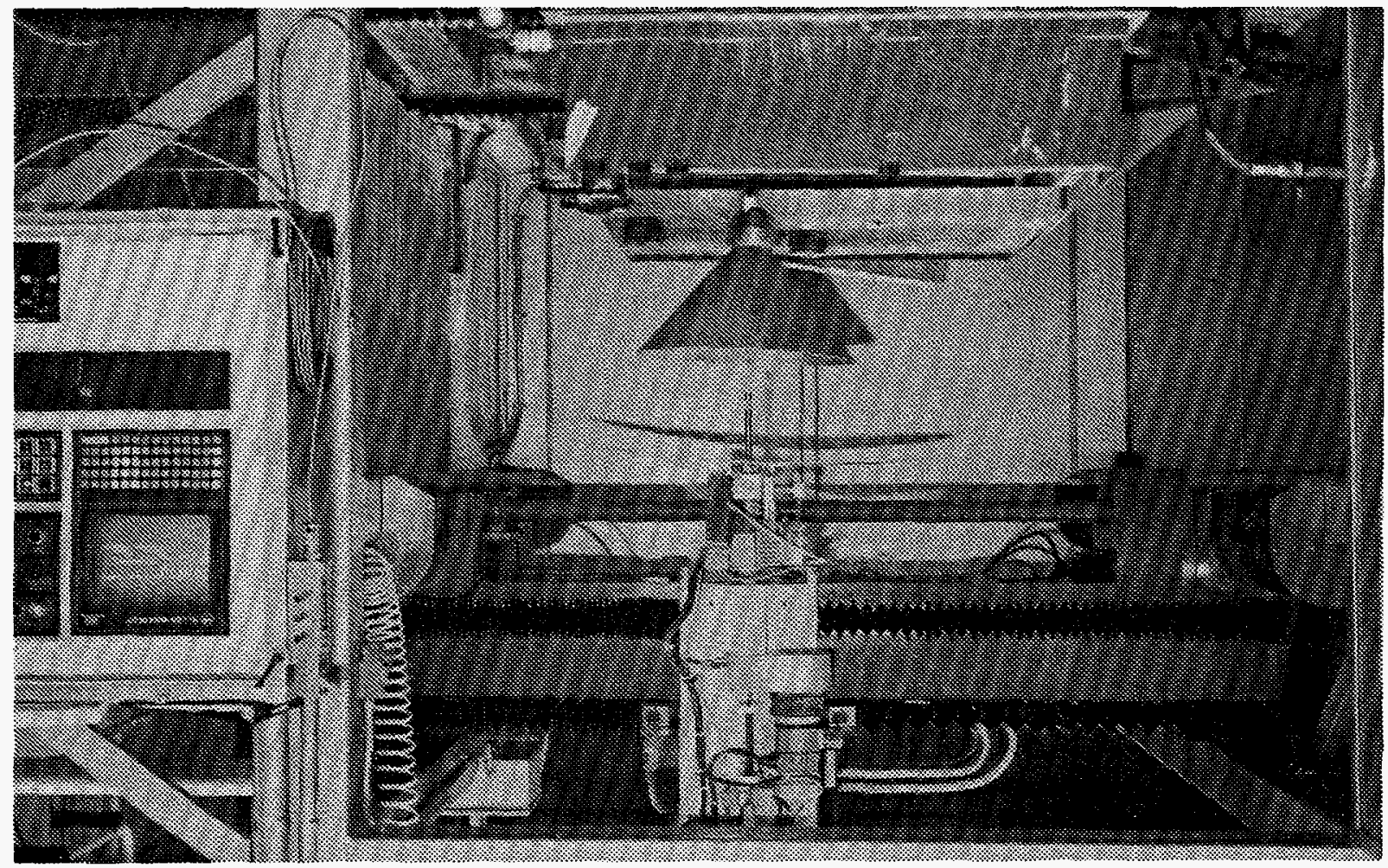




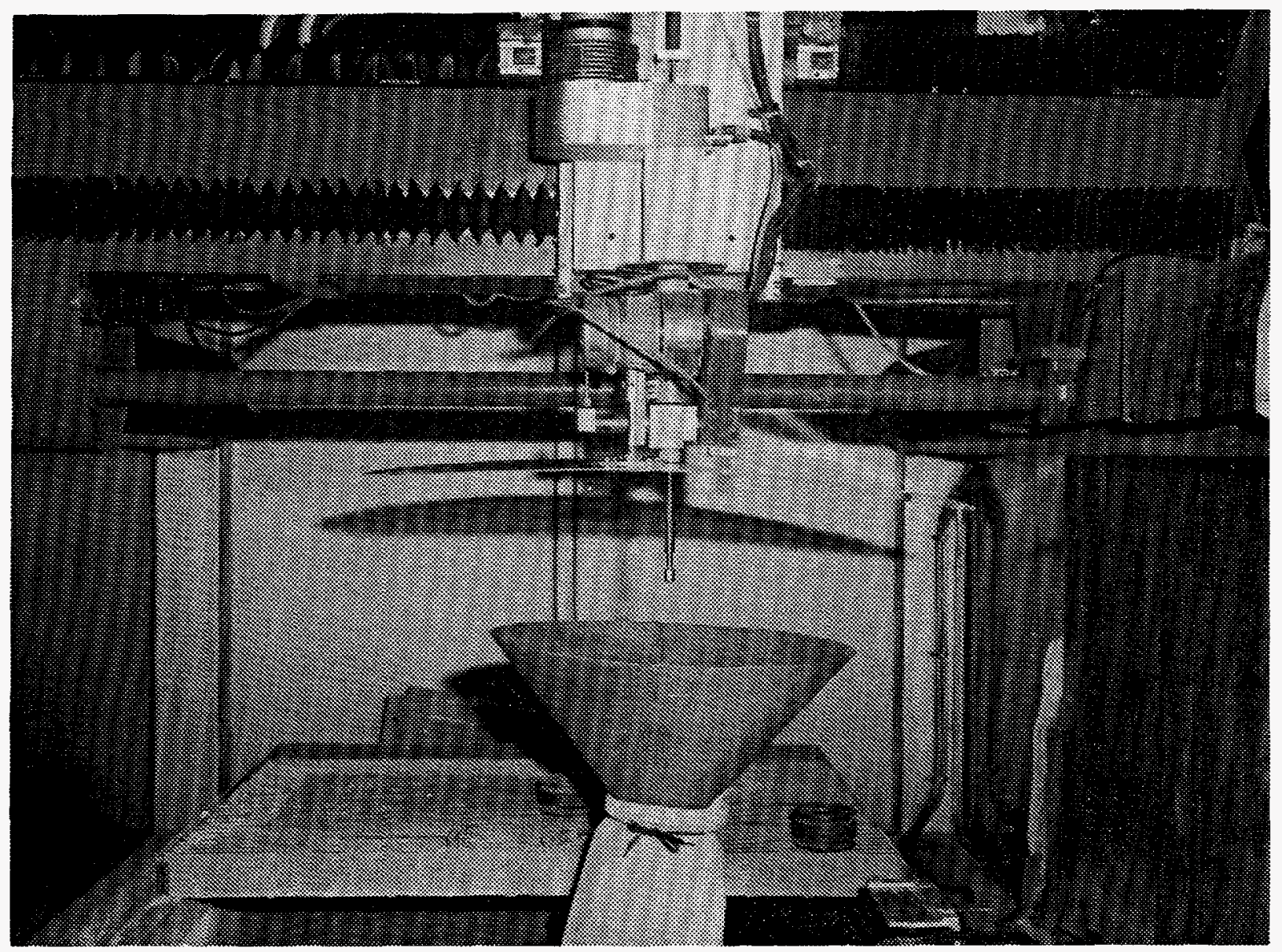

Figure 3. View of Work Cell Showing Wet Box Funnel with Filter Sock Attached and Plexiglas Cover

Size reduction of the LX-10 hemispherical shells was accomplished by positioning a shell in the funnel, with its equator up, and cutting in a spiral pattern starting at the center of the shell. Derivation of the spiral cutting patterns used in these experiments is shown in Appendix A. Spirals were programmed to move in the horizontal X-Y plane only and the nozzle was held constant at 1 inch above the equator of the part. All of these experiments used a 0.014-inch diameter nozzle moving at a feedrate of 50 inches/minute and with a waterjet cutting pressure of $30,000 \mathrm{psi}$.

A total of three LX-10 shells were used for these experiments. The first shell was preconditioned with liquid nitrogen and allowed to return to ambient temperature before cutting with the waterjet. It was felt this procedure might decrease the time required to reduce the shell to small particles and influence the final particle size but this was not the case. The initial cutting pattern on this first shell was a uniformly expanding spiral starting at its center and ending at the edge of the equator. This spiral pattern was not very efficient for cutting the shell for the following reasons: 1) Vertical thickness of the shell, as shown in Figure 4 , increases for $R$ in the range $\left(0, R_{\text {inner }}\right)$ and decreases for $R$ in the range $\left.\left(R_{\text {inner }}, R_{\text {outer }}\right), 2\right)$ interaction angle between the jet and the surface of the shell changes, as shown in Figure 5 , as the jet moves outward from the center of the shell to the inner edge of the equator. These problems were 
overcome by modifying the spiral pattern to allow $\mathrm{R}$ to expand at a decreasing rate as it approaches the equator of the part. This cutting pattern, shown in Figure 6, effectively cut the shell into large pieces which fell to the bottom of the funnel. These pieces were then cut into small particles using a second spiral cutting pattern - in this case a uniformly expanding spiral ending at $R=2$ inches as shown in Figure 7. Again, the nozzle was left at its original position 1-inch above the equator of the part.

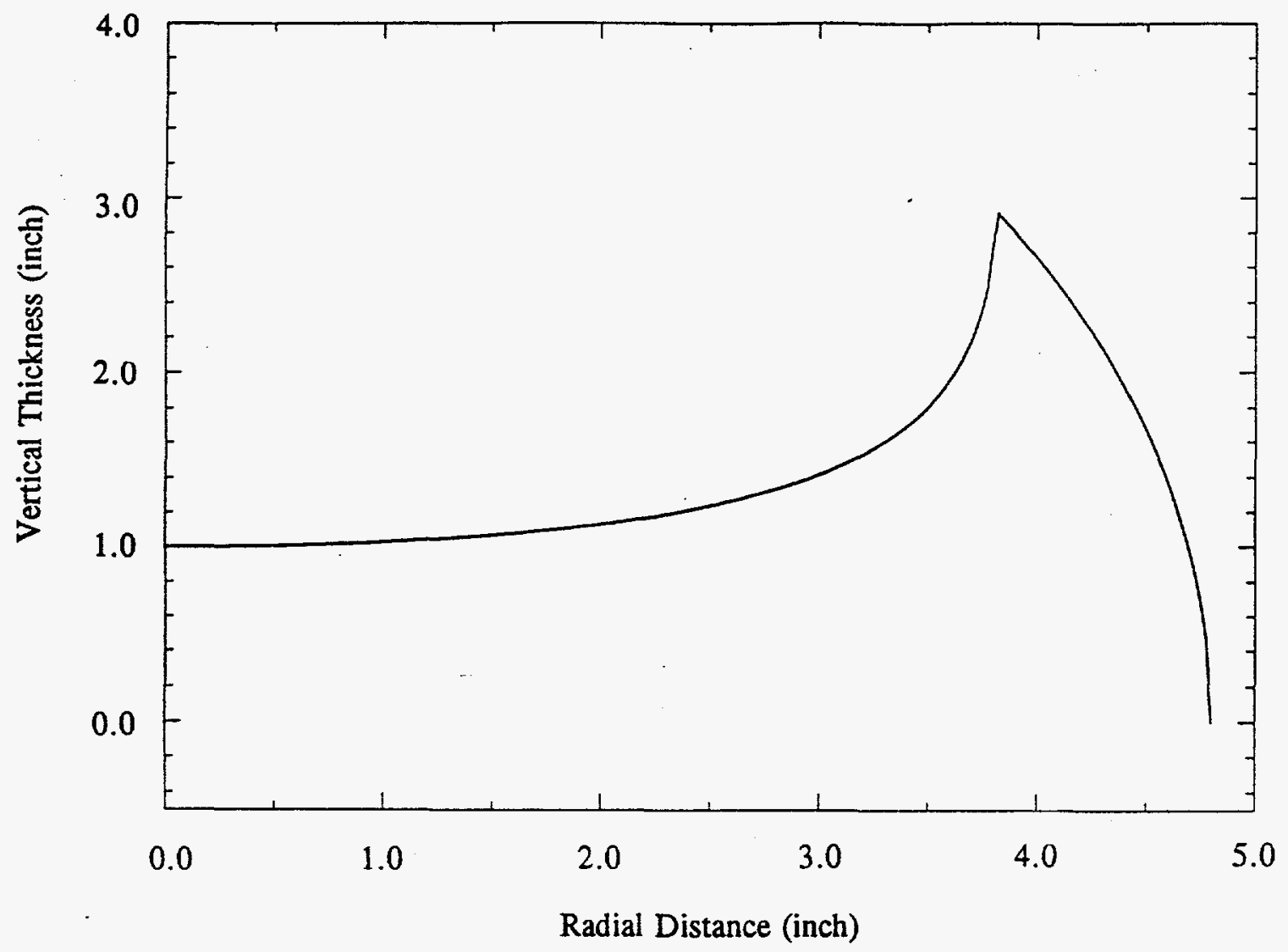

Figure 4. Variation in the Vertical Thickness of the Test Hemispherical Shells 


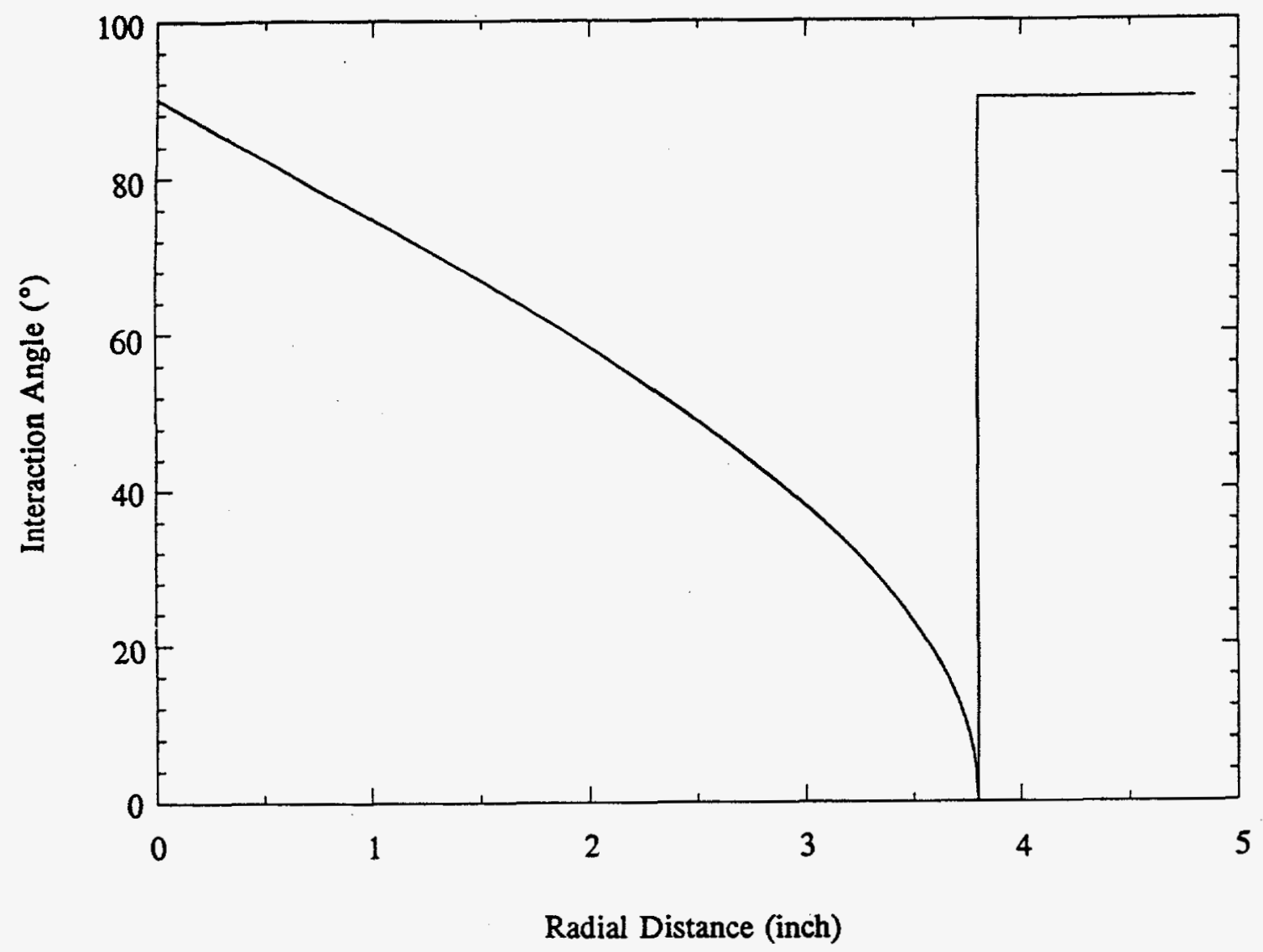

Figure 5. The Variation of the Interaction Angle Between Jet and Material Surface as a Function of Radial Distance from the Center of Hemispherical Shells 


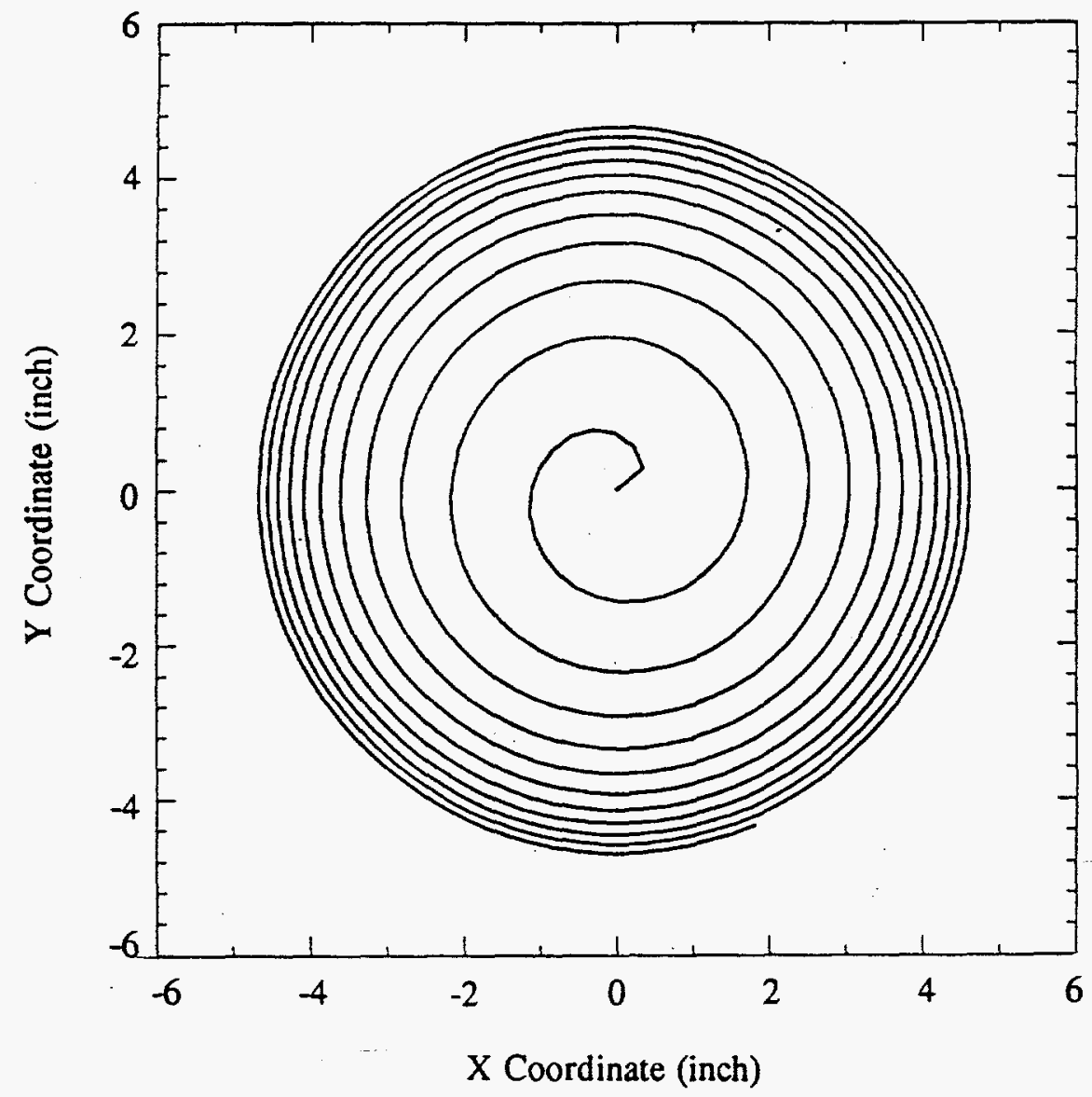

Figure 6. Spiral Cutting Pattern Showing Radius Expanding at a Reducing Rate

The spiral cutting patterns described above were used on each of the remaining two LX-10 shells. The first pattern, Figure 6, required two passes to reduce the billets to large pieces. The second pattern, Figure 7, required eight passes to reduce these pieces into small particles. This is because the pieces were free to move around in the funnel as the jet passed over them. A representative sample of the final product is shown in Figure 8. Total cutting time was 15 minutes for each part. Eleven gallons of waste water was generated for each of three shells. 


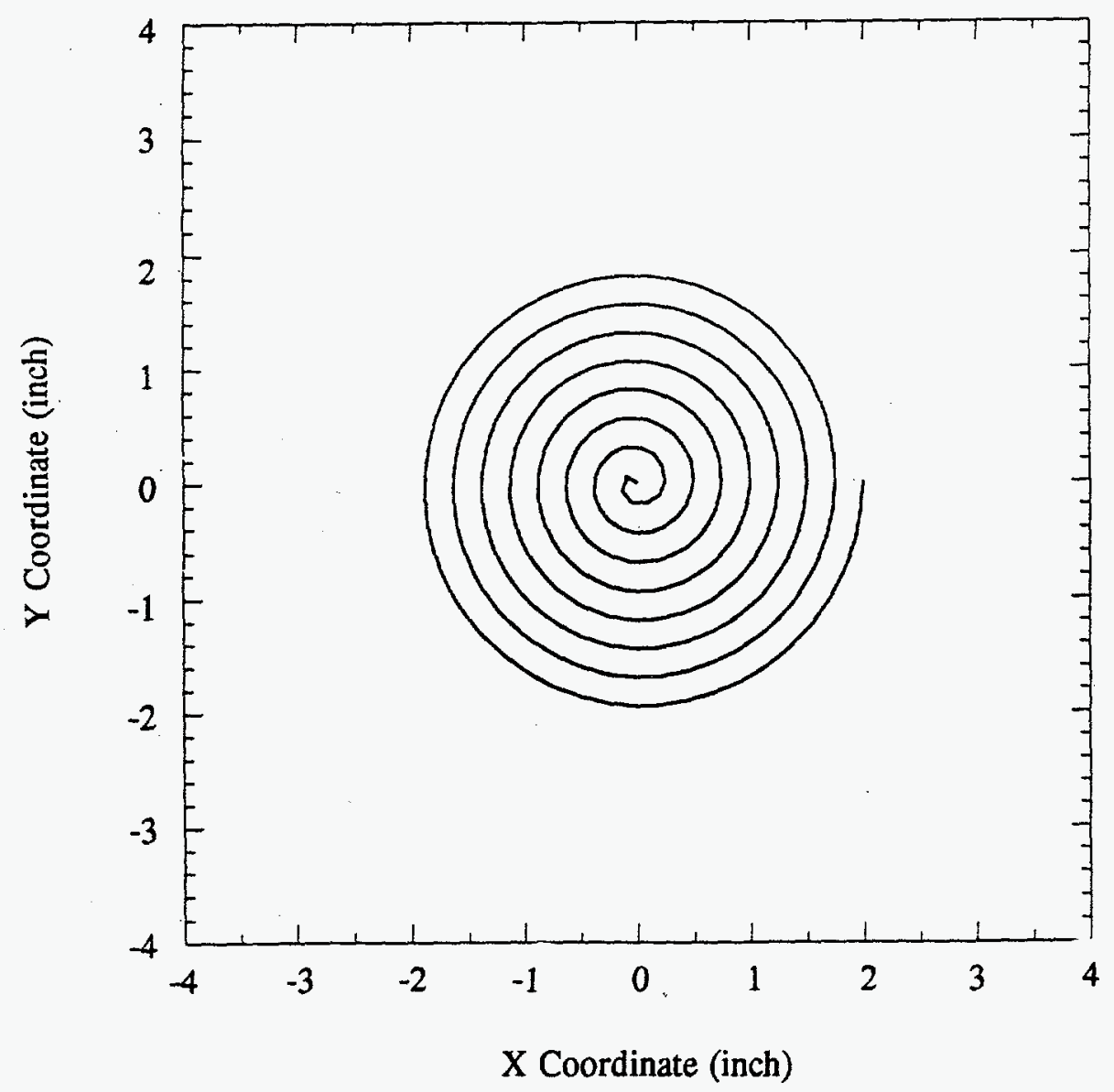

Figure 7. Uniformly Expanding Spiral Cutting Pattern

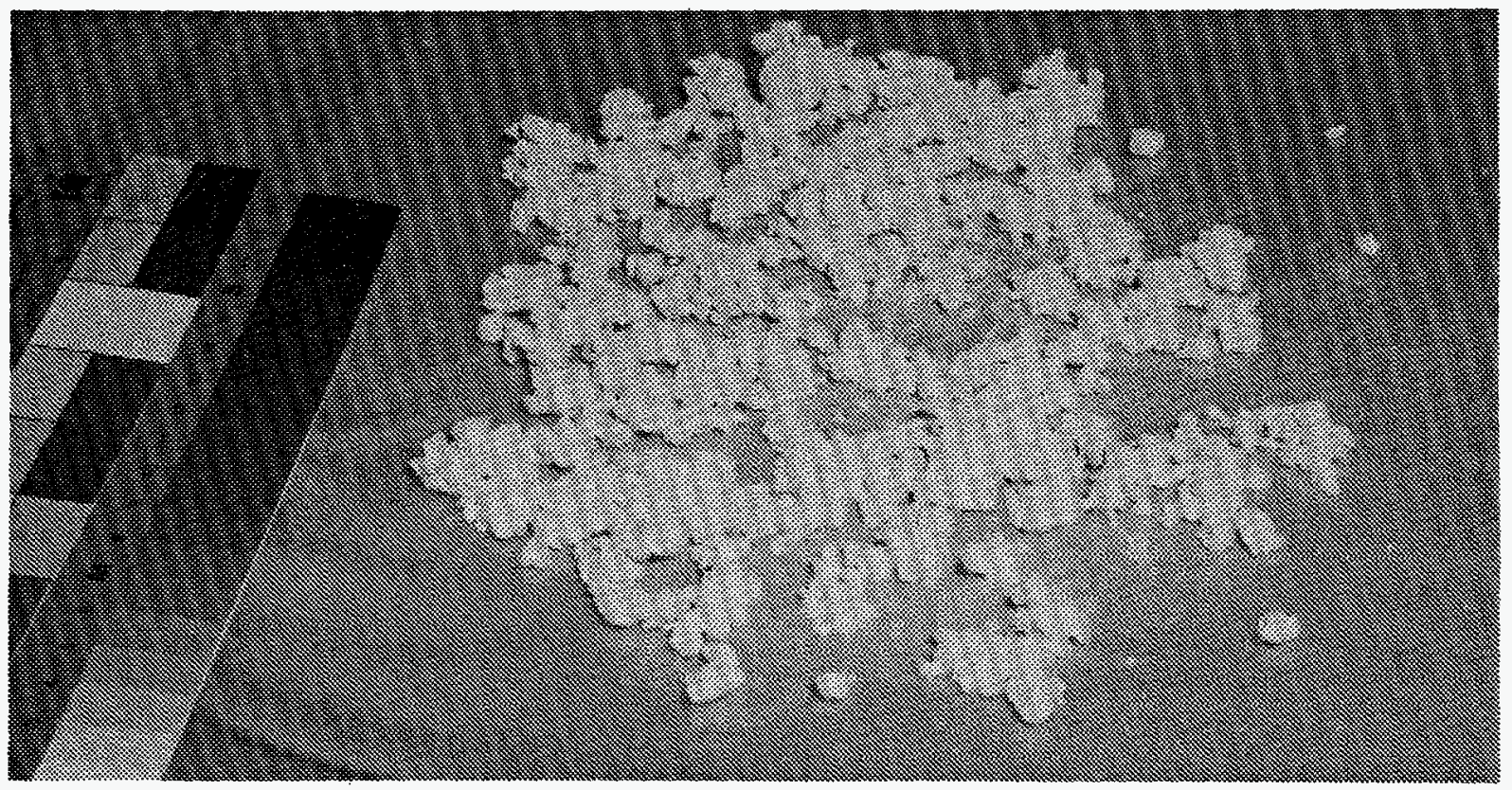

Figure 8. Photograph Showing Final Product After LX-10 Size Reduction Experiments 


\section{CONCLUSION}

Results of these experiments demonstrate the feasibility of using a waterjet to reduce hemispherical shells of LX-10 to a form that can be easily reprocessed. This technology can be extended to other explosive materials and shapes as well.

The waterjet method of size reduction produces less than one third the amount of waste water and requires less than one half the time to complete compared to conventional machining methods.

\section{ACKNOWLEDGEMENTS}

The authors gratefully acknowledge the helpful discussions with Sang-Wook Kang, Ed Villarreal, and Don Bretl of the Lawrence Livermore National Laboratory. 


\section{APPENDIX A}

A uniform spiral cutting pattern was derived from the argument that the radius changes by an amount of $R_{f} / N$ after a cycle of $2 \pi$, where $R_{f}$ is the final radius and $N$ is the number of cycles in one cutting pattern. $N$ does not need to be an integer. Then the spiral radius $\left(R_{1}\right)$ at any arbitrary point is

$$
R=\frac{R_{f}}{N} \frac{\theta}{2 \pi}
$$

$\theta$ is the traveling angle and its time derivative is

$$
\dot{\theta}=\frac{d \theta}{d t}=\frac{V}{R}
$$

$\mathrm{V}=$ Traveling speed for this model (not actual traveling speed of the nozzle).

From Equations 1 and 2 a differential equation for $\theta$ can be found in the following form:

$$
\theta d \theta=\frac{2 \pi V N}{R_{f}} d t
$$

Integrating both sides of Equation 3, for $\theta$ from 0 to $\theta$, and time from 0 to $t$, yields $\theta$ as a function of $t$.

$$
\theta=\sqrt{\frac{4 \pi V N t}{R_{f}}}
$$

Substituting Equation 4 into Equation 1, we have

$$
R=\sqrt{\frac{R_{f} V t}{\pi N}}
$$


From Equation 4 and 5 a spiral pattern can be produced similar to the one shown in Figure 7 of the text. This spiral pattern is not well suited for cutting hemispherical shells because of the variations in material thickness and cutting angle as the jet moves from the center of the part outward.

In order to allow for the variations of the vertical thickness and the interaction angle, the parameter $\mathrm{N}$ in Equation 1 should be changed to

$$
N-N_{i n t}+C \frac{\theta}{2 \pi}
$$

$\mathrm{C}=$ Constant

From Equations 1 and 6

$$
R=\frac{R_{f}}{N_{i n t}+C \frac{\theta}{2 \pi}} \frac{\theta}{2 \pi}
$$

from Equation 7, if we let $\theta=2 \pi$ and $\theta=N 2 \pi$, then we will have

$$
\begin{gathered}
R_{1}=\frac{R_{f}}{N_{i n t}+C} \\
R_{f}=\frac{R_{f}}{N_{i n t}+C N} N
\end{gathered}
$$

Then, in addition to the number of cycles $(N)$ in one cutting pattern, we also have to determine the spiral radius $\left(R_{1}\right)$ when it completes the first cycle $2 \pi$.

After a short calculation $\mathrm{C}$ and $\mathrm{N}_{\mathrm{int}}$ can be found in the following forms:

$$
C=\frac{R_{f}-N R_{1}}{R_{1}(1-N)}
$$

and

$$
N_{i n t}=\frac{N R_{1}-N R_{f}}{R_{1}(1-N)}
$$


The new spiral cutting pattern can be solved numerically using Equations 10 and 11 together with Equations 7 and 12.

$$
\Delta \theta=\frac{V}{R} \Delta t \quad(\Delta \mathrm{t}=\text { time step })
$$

The result is shown in Figure 6 of the text for the case of

$$
\begin{aligned}
& \begin{aligned}
R_{f} & =4.7 \text { inches, } \\
R_{1} & =1.4 \text { inches, }
\end{aligned} \\
& \text { and } \\
& N=10
\end{aligned}
$$

This spiral pattern was used in the first phase of water jet cutting of the explosive hemispheres and then the uniform spiral cutting pattern (Figure 7 of the text) was used to complete the process. 
DEPARTMENT OF ENERGY - WASHINGTON, DC

Director of Weapons Production

Office of Military Application

\section{DEPARTMENT OF ENERGY - AL}

Technical Information Officer, OIEA

Quality Operations Branch Weapons Quality Division

Technology Development Branch Weapons Quality Division

Waste Management Branch Waste Management and Operational Surety Division

Program Support Branch Weapon Programs Division

\section{DEPARTMENT OF ENERGY - AAO}

Area Manager

OFFICE OF SCIENTIFIC AND TECHNICAL INFORMATION - OAK RIDGE, TN

(2)

LAWRENCE LIVERMORE NATIONAL LABORATORY

$\mathrm{L}-32$

$L-282$ (6)

\section{LOS ALAMOS NATIONAL LABORATORY}

DX-DO

DX-10

$D X-16(3)$

ESA-2 Group Office

NWNP, F-630

ISD-4
SANDIA NATIONAL LABORATORIES - NEW MEXICO

Org. 2000
Org. 2571
Org. 2652
Org. 2600

$$
\text { *a }
$$

SANDIA NATIONAL LABORATORIES - CALIFORNIA

Org. 5354

\section{SAVANNAH RIVER LABORATORY}

Program Manager, Defense Waste Processing Section, 773-A

\section{ALLIED-SIGNAL INC. - KANSAS CITY PLANT}

Material Engineering

\section{MASON \& HANGER - PANTEX PLANT.}

\author{
Engineering and Design Division \\ ES\&HMM Directorate \\ Applied Technology Division \\ Program Management \\ Quality Division \\ Circulation Copy: \\ 1. W. A. Weinreich, 12-69 \\ 2. H. A. Woltermann, 11-2
}

Technical Library

File (5)

Please refer any distribution changes to

A. V. Lucero, Publications Section FTS 477-3535. 